\title{
Fluência Tecnológico-Pedagógica (FTP) dos Tutores
}

\author{
Elena Maria Mallmann - UFSM - elena.ufsm@gmail.com \\ Daniele da Rocha Schneider - PPGIE/UFRGS - dani.qme@ gmail.com \\ Mara Denize Mazzardo - 8CRE/DP/NTE - maradmazzardo@gmail.com
}

\begin{abstract}
Resumo: Este artigo é resultado de uma pesquisa-ação sobre a fluência pedagógica dos tutores em ambientes virtuais de ensino-aprendizagem. Os objetivos foram conceituar fluência tecnológico-pedagógica e mapear as opiniões dos tutores sobre a relevância da fluência tecnológico-pedagógica na tutoria. Realizou-se revisão bibliográfica e aplicouse questionário tipo survey aos tutores participantes de um curso de capacitação em fluência pedagógica. Os dados foram interpretados segundo a categoria mediação pedagógica. Como conclusões, ressalta-se que a atuação dos tutores precisa ser pautada com uma maior ênfase na fluência pedagógica para potencializar o processo ensinoaprendizagem mediado por tecnologias em rede.

Palavras-chave: Educação a Distância, Tutoria, Fluência Tecnológico-Pedagógica.
\end{abstract}

\section{Technological and Pedagogical Fluency of Tutors}

Abstract: This paper is the result of an action research about the pedagogical fluency of tutors in virtual teaching and learning environments. Its objectives were to conceptualize 'technological and pedagogical fluency' and to map the tutors' opinions regarding its relevance in tutoring. A literature review was carried out and a type survey questionnaire was applied to tutors that were participating in a pedagogical fluency training course. The data was interpreted according to the category of pedagogical mediation. Highlighted in the conclusion the tutors' performance needs to be guided with a greater emphasis in the pedagogical fluency in order to enhance the teaching and learning process mediated through network technologies.

Key-words: Distance Education, Tutoring, Technological and Pedagogical Fluency.

\section{Atribuições do Tutor no Processo Ensino-Aprendizagem}

As instituições que oferecem cursos na modalidade a distância definem as atribuições dos tutores de acordo com as concepções adotadas nos Projetos Políticos Pedagógicos e em consonância com o que as políticas públicas determinam. Pesquisas têm sido realizadas com o objetivo de identificar as atribuições dos tutores (SCHNEIDER, 2011; MALLMANN e SCHNEIDER, 2011; NUNES, 2013).

Dentre as várias atribuições dos tutores que aparecem na literatura sobre o assunto, pode-se destacar: conhecer os planejamentos e estratégias metodológicas adotadas pelo professor, mediar o processo ensino-aprendizagem, manter boa comunicação e interação com alunos e professor, acompanhar as atividades dos alunos com olhar investigativo, desafiar e instigar os alunos para o estudo e aprofundamento dos conteúdos, identificar as dificuldades dos alunos e agir com rapidez na busca de soluções, interatividade com o ambiente e materiais didáticos, problematizar os fóruns, incentivar o trabalho colaborativo. Evidencia-se que independente dos modelos e concepções, o que se pretende, em última instância, é que as atividades do tutor fortaleçam a aprendizagem dos alunos. "Os tutores são mediadores do processo de 
aprendizagem dos alunos e são fundamentais para criar situações que favoreçam à construção do conhecimento" (NUNES, 2013, p. 1).

Nunes (2013) analisou trabalhos publicados no Brasil e exterior, nos quais o tutor é considerado ator ativo e fundamental no processo de aprendizagem dos alunos. Dos 38 trabalhos analisados, de referências teóricas variadas, a pesquisadora elencou 64 sugestões de perfil, competências ou atribuições de tutores as quais foram classificadas nas categorias Conhecimento, Atitudes, Orientação, Comunicação (com os alunos), Ensino-aprendizagem, Atividades administrativas e interação com a equipe.

Na categoria Ensino-aprendizagem atribuições como: a) Estabelecer estratégias para solução dos problemas inerentes às atividades, b) Apresentar ideias ou caminhos para a resolução de uma atividade, c) Auxiliar os alunos a resolver questões pedagógicas que possam impedir o progresso no curso, d) Mediar o processo de aprendizagem, e) Respeitar o ritmo de aprendizagem do aluno, f) Traduzir o discurso científico para forma narrativa, auxiliando o aluno na compreensão do conteúdo foram citadas em $66 \%$ das 64 sugestões elencadas. Esses dados indicam a relevância do trabalho do tutor no processo de aprendizagem dos alunos.

$\mathrm{Na}$ pesquisa realizada por Mallmann e Schneider (2011), na qual foram analisadas as atribuições dos tutores nas publicações científicas nos anais do congresso anual da Associação Brasileira de Educação a Distancia (ABED) no período de 2006 até 2010, um dos aspectos destacados é o aumento do nível de exigência nas atribuições dos tutores. Sobre comunicação em 2006: enviar e receber e-mail; interagir por meio das ferramentas de comunicação. Em 2010: promover a interatividade e a construção de vínculos afetivos; manter o ânimo e presença virtual dos alunos no curso; mediar os conflitos e solucionar os problemas. Na mediação do processo ensino-aprendizagem, em 2006: acompanhar e avaliar a aprendizagem e em 2010: possuir uma clara concepção de aprendizagem; dominar bem o conteúdo; facilitar a construção de conhecimentos pelo aluno; acompanhamento das tarefas individuais; estimular o aluno a analisar os problemas de forma crítica; monitorar eletronicamente as atividades de estudo.

Diante desse panorama, percebe-se que o tutor é integrante fundamental na estruturação da modalidade a distância que temos no Brasil. No sistema da Universidade Aberta do Brasil (UAB), atua diretamente com os alunos no processo ensino-aprendizagem e no documento Referenciais de Qualidade para Educação Superior a Distância o tutor é caracterizado "como um dos sujeitos que participa ativamente da prática pedagógica. Suas atividades desenvolvidas a distância e/ou presencialmente devem contribuir para o desenvolvimento dos processos de ensino e de aprendizagem e para o acompanhamento e avaliação do projeto pedagógico" (BRASIL, 2007, p. 21).

No referencial são destacadas as funções dos tutores a distância e presencial, sendo que o tutor a distância media o processo pedagógico junto aos alunos geograficamente distantes, esclarecendo dúvidas e promovendo espaços de construção coletiva do conhecimento (BRASIL, 2007). O tutor presencial atende os alunos no polo, tendo que ser conhecedor do projeto pedagógico, dos conteúdos e materiais didáticos do curso para poder auxiliá-los nas atividades individuais e em grupo, incentivando a pesquisa e esclarecendo dúvidas sobre os conteúdos e tecnologias utilizadas. Deve, também, participar dos momentos presenciais, como atividades práticas nos polos. Tanto para os tutores a distância como os presenciais o conhecimento dos conteúdos curriculares do curso é imprescindível (BRASIL, 2007). 


\section{Fluência Tecnológico-Pedagógica (FTP)}

A atividade do tutor acontece na mediação das diversas situações de aprendizagem planejadas, normalmente pelo professor. Desse modo, entende-se ser necessário para um melhor desempenho da tutoria desenvolver e aprimorar Fluência Tecnológica e Pedagógica. A mediação pedagógica é potencializada pela atuação dos professores, tutores e alunos (humanos) aliados aos artefatos didático-pedagógicos impressos e hipermidiáticos (não humanos), abrangendo a relação das pessoas entre si (interação), a relação das pessoas com o saber (interatividade) e todos os mediadores que a potencializam (MALLMANN, 2008).

Souza, Sartori e Roesler (2008) destacam que a Educação a Distância (EaD) é um processo caracterizado por duas formas de mediação: a humana e a tecnológica as quais estão imbricadas uma na outra. $O$ entrelaçamento nas formas de mediação também é destacado por Schlemmer (2011) ao afirmar que o conhecimento tanto tecnológico digital quanto pedagógico estão totalmente imbricados e são materializados no desenvolvimento das práticas pedagógicas. O tutor necessita desenvolver e aprimorar FTP para melhor desempenhar a diversidade de atribuições e contribuir para a obtenção de bom aproveitamento dos alunos e qualidade do curso no qual atua.

Um dos aspectos essenciais da FTP é capacidade de produzir informações e transformá-las em conhecimento, ou seja, conteúdos, passando da condição de usuário para a de autor e coautor. Castell (1999) afirma que as tecnologias não são simplesmente ferramentas a serem aplicadas, mas processos a serem desenvolvidos, de modo que usuários e criadores possam compartilhar funções. Para Schneider (2011)

\footnotetext{
Ser fluente tecnologicamente significa conhecer e apropriar-se das ferramentas educacionais, seus princípios e aplicabilidade em diferentes situações. Criar, corrigir, modificar interativamente diferentes ferramentas e artefatos, compartilhando novos conceitos, funções, programas e ideias. Aplicar de forma sistemática e cientificamente os conhecimentos, adaptandoos as próprias necessidades de cada contexto (p. 82).
}

FTP é um processo contínuo de conhecimento, exploração e produção com recursos variados. A atuação do tutor é associada "aos métodos, técnicas e ferramentas que conduzem à potencialização dos processos de aprendizagem. $O$ tutor passa a monitorar, nos Ambiente Virtuais de Ensino Aprendizagem (AVEA), recursos e atividades, levando o estudante a construir o conhecimento mediante um processo de interação" (SCHNEIDER, 2011, p. 75).

O tutor ao monitorar no ambiente virtual, os recursos e atividades dos alunos está trabalhando com conhecimentos técnicos, práticos e emancipatórios, portanto, pedagógicos. Recursos e atividades foram definidas no planejamento didático do professor e o tutor precisa conhecer os conteúdos, o planejamento, o material didático, o qual pode estar organizado com recursos hipermídia e as atividades definidas de acordo com os objetivos e conteúdos (envolvendo os alunos, problematizando, instigando, desafiando). Nesse contexto, além da fluência tecnológica o tutor precisa da fluência pedagógica. $\mathrm{O}$ apoio do tutor fluente tecnológica e pedagogicamente é essencial para orientar as ações dos alunos e contribui para o desenvolvimento de habilidades que os levam a conquistar a autonomia (MALLMANN et al, 2012).

Mas o que é Fluência Tecnológico-Pedagógica? Fluência possui características (aproximações) com o conceito de performance (MALLMANN, 2008). Schechner 
(2000), citado por Conte (2013, p. 405), afirma que a performance “está em todo lugar, enfatizando o ambiente cada vez mais midiatizado em que vivemos, onde nos comunicamos continuamente por uma quantidade ilimitada de meios virtuais". O tutor, que trabalha diretamente com o aluno, utiliza recursos de comunicação e precisa de performance/fluência para conseguir interação. Comunicação, mediação e aprendizagem são conceitos intimamente ligados e representam um ponto-chave para a qualidade da EaD (SEVERO et. al, 2011). Da mesma forma, na orientação e acompanhamento dos estudos e realização das atividades dos alunos a "força da performance como formação na dinâmica de uma prática educativa radical, estimuladora da curiosidade crítica, à procura das razões de ser dos fatos, como forma de ação especificamente humana, que se funda na interdisciplinaridade" (CONTE, 2013, p. 405) é um diferencial na atuação do tutor.

A fluência reúne conhecimentos e práticas, teoria e ações, é saber fazer o melhor em cada situação, com cada recurso, sendo que não acontece no improviso, é resultado de formação. Possibilita a articulação do processo ensino-aprendizagem, indica maior nível de aprendizagem, a qual responde pela mudança de comportamento com obtenção de êxito em um saber fazer (PIAGET, 1974). Envolve não apenas saber como usar ferramentas tecnológicas, mas também saber como construir coisas significativas com essas ferramentas (PAPERT e RESNICH, 1995) na medida em que situações problemáticas precisam ser resolvidas.

A FTP é desenvolvida com a utilização, experimentação e a abstração em diversas situações. Através do diálogo, das problematizações, das interações o tutor contribui com a aprendizagem que é um processo individual, interno e de cada sujeito (PIAGET, 1974). Ao problematizar de forma sistemática e cientificamente os conhecimentos, adaptando-os as próprias necessidades tanto nas interações quanto no monitoramento do processo de estudo, o tutor contribui para a resolução das situaçõeslimite, transformando a prática educativa em caminho para a emancipação (autonomia, autoria e coautoria) dos alunos.

A complementaridade entre o pedagógico e tecnológico vem ao encontro de uma das dez competências que Perrenoud (2000) destaca serem fundamentais: conhecer as possibilidades e dominar os recursos. Esse conhecimento permite aos tutores, junto com os professores, reconhecer, avaliar e tomar decisões em relação à potencialidade de cada ferramenta em virtude dos objetivos e dos conteúdos a serem propostos aos alunos. Implica diálogo em torno dos problemas e reflexão compartilhada acerca das soluções encontradas. Essa "co-participação dos sujeitos no ato de pensar se dá na comunicação" (FREIRE, 1979, p.66), que potencializa o desenvolvimento de argumentos mais apurados, melhorando as instâncias do ensinar, aprender e investigar.

O conhecimento das possibilidades da ferramenta tecnológica viabiliza a implementação de atividades relevantes pedagogicamente e contribui para a melhoria da qualidade do ensino. Sendo a aprendizagem um processo sempre em construção, a criação de condições de integração da tecnologia a prática pedagógica perpassa de um conhecimento para outro mais complexo. Essas releituras das possibilidades são necessárias ao tutor para que ele coloque em "cheque" seu modo de pensar e, a partir desse desequilíbrio, produza uma nova possibilidade pedagógica, confrontando certezas anteriores.

Esse processo contínuo de modificações de ações e pensamentos vai aperfeiçoando a mediação do tutor sobre as potencialidades imbricadas em cada recurso tecnológico, o qual ocorre por meio de um duplo movimento de assimilação às 
estruturas e acomodação dessas ao real (PIAGET, 1996). A experiência da interação é essencial para que o tutor utilize as interfaces de comunicação como potencializadoras de problematizações, questionamentos, confronto de ideias e soluções.

A ação do tutor diante de situações-limite gera desconforto, desequilíbrio que é provocado pelo desconhecido. Fato esse que para Piaget (1976) desencadeia a construção do conhecimento. A interação com o objeto, que se caracteriza como qualquer coisa que o sujeito aborda como diferente de si (outro sujeito, conceito, imaginário, ferramenta tecnológica), provoca sucessivas transformações no pensar e agir do tutor (transformações de esquemas) e essas reelaborações de pensamentos resultam de processos de equilibração majorante (saber fazer + compreender) que vão tentar estabilizar os desequilíbrios provocados pelo objeto (PIAGET, 1976). Esse reequilíbrio não necessariamente é o retorno ao estado anterior e sim para um mais elaborado que enriquece o processo. Ao incorporar o recurso educacional aos seus esquemas, os mesmos se ajustam às características do sujeito e transformam-se, caracterizando a compreensão do tutor sobre determinada situação, a partir de um conflito cognitivo por ele anteriormente instalado.

O tutor tem possibilidade de construir seu conhecimento ao agir sobre o recurso educacional, retirar informações desse objeto (abstração empírica) e aplicar as próprias conclusões sobre sua ação (abstração reflexiva) à diferentes etapas da mediação pedagógica. Ao refletir sobre determinada possibilidade didática, está agindo sobre o objeto a partir da experimentação e retira dessa ação informações, possibilitando em determinados momentos a realização de abstrações reflexionantes que possibilitam a construção de conhecimentos novos (PIAGET, 1974).

Em determinados momentos, a abstração empírica é suficiente para dar continuidade às interações e monitoramento do processo ensino-aprendizagem. No entanto, o desafio do tutor com FTP é chegar a realizar abstrações reflexionantes sobre as inúmeras possibilidades que os recursos educacionais têm a oferecer para potencializar mediação pedagógica. FTP se desenvolve ao agir sobre o objeto transformando-o, modificando-o adaptando-o ao contexto e aos objetivos de situações educacionais específicas.

Considerando os autores pesquisados e as políticas públicas consultadas podemos conceituar FTP como a capacidade de mediar o processo de ensinoaprendizagem com conhecimentos sobre planejamento, estratégias metodológicas, conteúdos, material didático, tecnologias educacionais em rede com destaque para os AVEA, realização de ações com os alunos para desafiar, dialogar, problematizar, instigar a reflexão e a criticidade, incentivar a interação com o grupo e interatividade com ambiente e materiais didáticos, o desenvolvimento de trabalhos colaborativos, a autonomia, autoria e coautoria, a emancipação, monitorar o estudo e realização das atividades dos alunos identificando dificuldades e propondo soluções, manter boa comunicação no ambiente virtual com todos os envolvidos, reflexão sobre as potencialidades didáticas dos recursos utilizados, práticas didáticas implementadas e sobre a própria atuação na tutoria.

A partir dessas reflexões e análises, resumidas na Figura 1, infere-se que a FTP consiste na clareza epistemológica, conhecimento dos conteúdos curriculares e questões didático-metodológicas que peculiarizam o processo ensino-aprendizagem. 


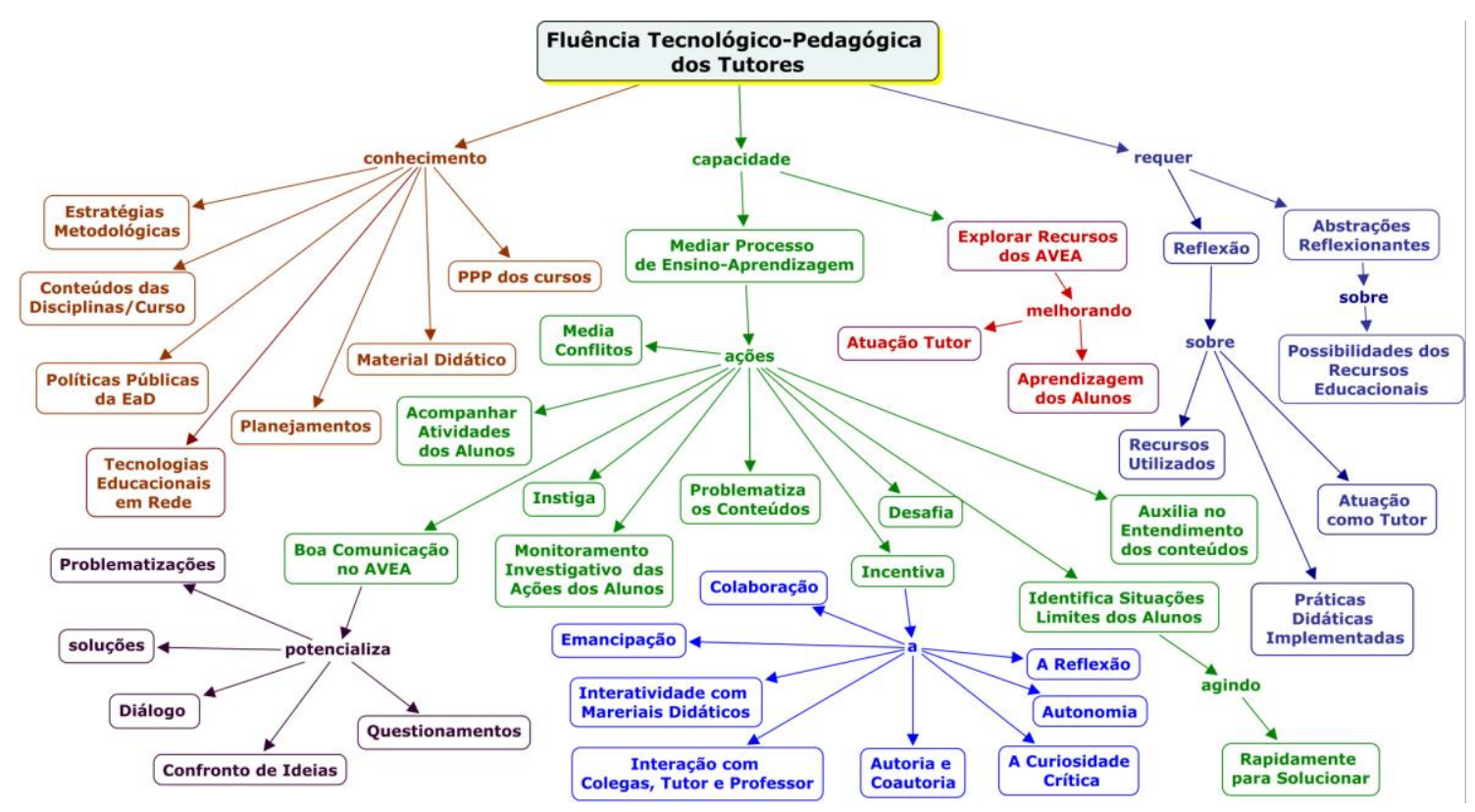

Figura 1- Fluência Tecnológico-Pedagógica dos Tutores

\section{Estratégia Metodológica}

O estudo se constitui numa pesquisa-ação sobre a FTP dos tutores em ambientes virtuais de ensino-aprendizagem. Realizamos revisão bibliográfica sobre FTP e identificamos as opiniões dos tutores sobre a relevância do conhecimento dos aspectos organizacionais do conteúdo, disciplinas e modalidade na tutoria, através da análise de resultados de um questionário tipo survey. A pesquisa survey é um meio de "adquirir informações sobre as características, ações ou opiniões de um grande grupo de pessoas, representantes de uma população" (TANUR apud PINSSONNEAULT \& KRAEMER, 1993, p. 6).

O questionário survey foi respondido por cursistas de três turmas do curso Capacitação em Fluência Pedagógica para Tutores implementado na Universidade Federal de Santa Maria: Turmas 1 e 2 de 2012 e Turma 1 de 2013, totalizando 138 respostas. O questionário foi aplicado para os cursistas avaliarem o curso com um total de 34 questões divididas em 5 categorias das quais elegemos, nesse texto, a "mediação pedagógica" como categoria de análise. Analisamos 5 questões fechadas da categoria "mediação pedagógica" e a questão aberta relacionada à comentários e sugestões dos tutores.

\section{Resultados e Discussões}

Analisamos 4 questões da categoria mediação pedagógica e a questão aberta na qual os cursistas inseriram comentários e sugestões. A primeira questão (Figura 2) é sobre a necessidade do tutor conhecer aspectos pedagógicos e organizacionais da EaD para implementação de sua prática. A quase totalidade dos cursistas (99\%), concordaram com essa assertiva, mostrando ser fundamental o conhecimento sobre os aspectos pedagógicos para exercer a tutoria. No entanto, na questão 5 (Figura 3) que é sobre duas atribuições dos tutores (monitoramento e problematização dos conteúdos), 
ocorre uma divergência na opinião, pois 20 cursistas (14\%) concordaram apenas em parte.

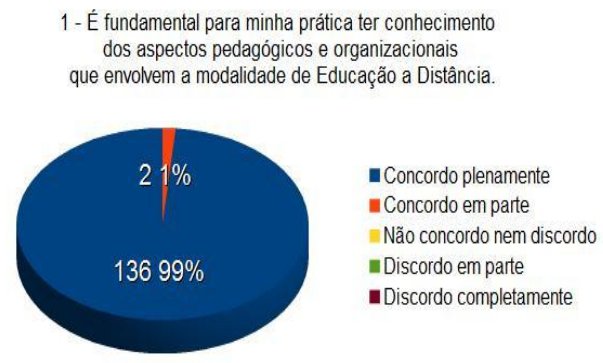

Figura 2 - Aspectos pedagógicos e organizacionais da $\mathrm{EaD}$

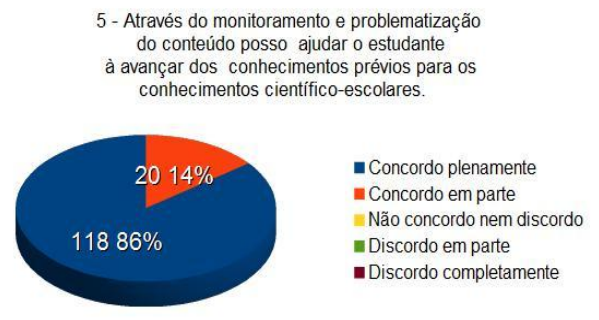

Figura 3 - Monitoramento e problematização dos conteúdos

Essa divergência sugere diferentes interpretações. Os tutores tem clareza da necessidade de formação pedagógica, mas alguns não assimilaram o monitoramento e problematização dos conteúdos como ações que podem ser qualificadas com o aprimoramento da fluência pedagógica.

Para os alunos de cursos a distância, os conteúdos (em torno dos quais deve ocorrer a construção do conhecimento) se tornam explícitos à medida que acessam recursos e realizam atividades de estudo. Nesse contexto, o tutor ao problematizar as informações dos materiais didáticos, fazendo com que os alunos exponham ideias e pensamentos reflexivos, colabora efetivamente com o desenvolvimento dos conhecimentos científicos-escolares.

Esse confronto de conhecimentos prévios com situações complexas do conhecimento científico instiga a autonomia do aluno em relação ao próprio processo de aprendizagem. Implica uma mediação com intenção, "que não pode ser ingênua, mas manifestar os propósitos do que se deseja atingir: a promoção do encontro e a construção do conhecimento" (BRUNO, 2007, p. 203), ações essas potencializadas na medida em que o tutor amplia a FTP.

A fluência pedagógica relaciona-se à clareza didática e compreensão que o tutor possui sobre os conteúdos curriculares e a organização didático-metodológica do curso, aspectos esses que auxiliam no desenvolvimento de interação e respostas para as situações-limites dos alunos. Nas palavras de Pallof \& Pratt (2002), o tutor exerce a função pedagógica ao propiciar aos alunos um ambiente social que instigue a aprendizagem. Para isso, precisa utilizar os recursos didáticos disponibilizamos pelo professor.

A compreensão das bases epistemológicas e concepção de educação que estão embricadas e fundamentam o curso, assim como, a clareza de que sujeito se quer formar influenciará diretamente na interação entre professor/tutor/aluno e sua relação com o conhecimento. Essa fluência pedagógica viabiliza a interação e possibilita que o tutor desafie o aluno em relação as situações-limite.

Quando os cursistas foram questionados sobre a fluência pedagógica ser essencial para compreensão do conteúdo e estabelecimento de relações entre os objetivos e enunciados das atividades de estudo (Figura 4), 81\% concordaram plenamente. Porém 23 cursistas (17\%) concordaram em parte, 2 cursistas (1\%) discordaram completamente e 1 cursista (1\%) se absteve (não concordou nem discordou). Desenvolver FTP é essencial para compreensão dos conteúdos e estabelecer relação entre os objetivos e enunciados das atividades de estudo. O fato de 19\% 
concordarem em parte ou não concordarem com a afirmação é preocupante, pois a fluência pedagógica possibilita contextualização, explicações, exemplificações, utilizando outros termos quando necessário, sem perder o significado central dos conteúdos.
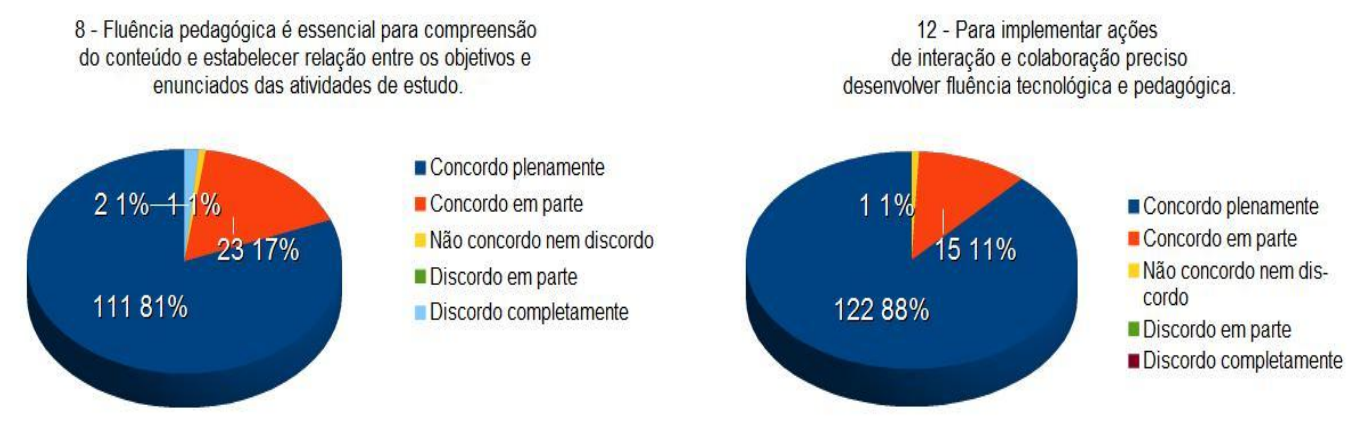

Figura 4 - Fluência pedagógica do tutor

Figura 5 - Fluência tecnológico-pedagógica

A mediação, como uma ação de intervenção no desenvolvimento da aprendizagem dos alunos, está articulada aos conteúdos, sujeitos e ferramentas tecnológicas. Nesse contexto, ao serem questionados sobre a necessidade de FTP na implementação de ações de interação e colaboração (Figura 5), a maioria dos cursistas $(88 \%)$, afirmam que sim, $11 \%$ concordam em parte e $1 \%$ não concorda nem discorda.

Para que a interação e colaboração se efetive com qualidade num ambiente virtual, o tutor precisa desenvolver FTP, pois constitui-se num "empoderamento" (FREIRE e \& SHOR, 1997) ao tutor, articulado à dimensão didática do processo ensinoaprendizagem.

Como na EaD a mediação pedagógica ocorre essencialmente por meio de ambientes digitais, as tecnologias auxiliam no processo de interação e colaboração, pelas quais o tutor incentiva os questionamentos, reflexões e posicionamentos autônomos. Nesse sentido, não basta somente a fluência pedagógica em relação ao conteúdo específico e formas de ensinar. É preciso também a fluência tecnológica que possibilita e potencializa o processo ensino-aprendizagem, sendo necessário ao tutor apropriar-se dessa a fim de compreendê-la no campo das possibilidades pedagógicas.

Fluência pedagógica e tecnológica são convergentes, inseparáveis na modalidade a distância. Isso ficou evidente também na opinião dos cursistas no campo comentários e sugestões do questionário survey, dos quais destacamos: "Acredito que o curso foi interessante para agregar conhecimento sobre a prática pedagógica dentro da atividade de tutoria." "Foi fácil perceber que a função exercida pelo tutor não se limita a ser o mediador entre participantes e professor. Faz-se necessário compreender o conteúdo da disciplina, agir pedagogicamente para que o grupo possa atingir o aprendizado." "Destinar uma parte da aula para o manuseio dos recursos tecnológicos."

A preocupação dos tutores com a FTP está sempre presente mas, demonstram uma preocupação maior com atividades de conhecimento técnico em detrimento de formação teórico-conceitual. Portanto, para desenvolver e aprimorar FTP, é necessário 
investir em capacitação dos agentes constituintes dos sistemas de $\mathrm{EaD}$, tais como o tutor. Assim, pode-se viabilizar a implementação de suas atribuições, as quais estão parametrizadas pelas políticas públicas nacionais.

\section{Considerações Finais}

A FTP relaciona-se ao conhecimento dos conteúdos curriculares e questões didático-metodológicas que perpassam o processo ensino-aprendizagem mediado por tecnologias educacionais em rede. Ao desenvolver e aprimorar FTP, o tutor tem maiores condições de mediar conflitos, auxiliar no entendimento dos conteúdos através da problematização, acompanhar as atividades dos alunos, instigar, identificar situaçõeslimite e agir sobre essas com rapidez. O tutor que conhece e compreende as políticas públicas, os projetos pedagógicos, os planejamentos, as estratégias metodológicas e os conteúdos curriculares, potencializa sua mediação através da reflexão, autoria e coautoria, colaboração, interação, interatividade e emancipação que são aspectos e ações essenciais do processo ensino-aprendizagem.

No entanto, a partir dos dados analisados verifica-se que há necessidade de avançar em relação à compreensão dos princípios da FTP e suas especificidades em relação à mediação dos tutores. Isso significa dizer que a atuação dos tutores precisa ser pautada com uma maior ênfase tanto nos aspectos pedagógicos quanto tecnológicos da fluência requerida no processo ensino-aprendizagem mediado por tecnologias educacionais em rede.

Os tutores afirmam ser relevante ter FTP, porém ao apresentarem sua opinião sobre os conteúdos de curso de capacitação solicitam maior ênfase em conhecimentos técnicos. Isso demonstra que continuam centrando-se mais no aprimoramento dos aspectos tecnológicos da fluência sem compreenderem a mesma como entrelaçadas às questões pedagógicas da natureza do trabalho docente e da tutoria na modalidade a distância.

Nesse sentido, é necessário continuar investindo na formação dos tutores com vistas ao alcance da compreensão dos aspectos relacionados à questões didáticometodológicas e tecnológicas que contribuem para a implementação de suas atribuições na mediação a distância. Portanto, desenvolver e aprimorar FTP é condição sine qua non para o exercício da tutoria em cursos mediados por tecnologias educacionais em rede.

\section{Referências Bibliográficas}

BRASIL. Ministério da Educação. Secretaria de Educação a Distancia.

Referências de qualidade para educação superior a distância. 2007. Disponível em: http://portal.mec.gov.br/seed/arquivos/pdf/legislacao/refead1.pdf Acesso em: 25 ago. 2013.

BRUNO, A. R. A aprendizagem do educador: estratégias para a construção de uma didática on-line. Programa de Pós- Graduação em Educação: Currículo, 2007. 352p. Tese de doutorado.

CASTELLS, M. A Sociedade em Rede. São Paulo: Paz e Terra. 1999.

CONTE, E. Repensando a performance na educação - intuições e problemas na recepção. Educação, Santa Maria, maio/ago. 2013. Disponível em:

http://dx.doi.org/10.5902/198464443978 Acesso em: 11 out.2013 
FREIRE, P. Extensão ou comunicação. Rio de Janeiro: Paz e Terra, 1979.

FREIRE, P.; SHOR, I. Medo e ousadia: o cotidiano do professor. $7^{\mathrm{a}}$. ed. São Paulo: Paz e Terra, 1997.

MALLMANN, E. M. Mediação pedagógica em educação a distância: cartografia da performance docente no processo de elaboração de materiais didáticos.

Florianopolis: UFSC/PPGE, 2008. 304p. Tese de doutorado.

MALLMANN, E. M. et al. Fluência Tecnológica dos Tutores em Ambientes Virtuais. In: RENOTE, V. $10 \mathrm{~N}^{\circ}$ 1, julho, 2012. Disponível em:

http://seer.ufrgs.br/renote/article/viewFile/30821/19193 Acesso em: 12 set. 2013

MALLMANN, E. M.; SCHNEIDER, D. R. Tutoria em Educação a Distância:

indicadores para Políticas Públicas. In: $17^{\circ}$ Congresso Internacional ABED de Educação a Distância, Manaus: ABED, 2011. Disponível em:

http://www.abed.org.br/congresso2011/cd/111.pdf Acesso em: 10 set. 2013.

NUNES, V. B. O Papel do Tutor na Educação a Distância: O Estado da Arte. In: Congresso Brasileiro de Ensino Superior a Distância, 10., 2013, Belém-PA. Anais, Congresso Brasileiro de Ensino Superior a Distância, 2013. Disponível em: http://www.aedi.ufpa.br/esud/trabalhos/oral/AT2/114143.pdf

Acesso em: 25 set. 2013

PALLOF, R. M.; PRATT, K. Construindo comunidades de aprendizagem no ciberespaço. Porto Alegre: Artmed. 2002.

PAPERT, S.; RESNICK, M. Technological Fluency and the Representation of Knoledge. Proposal to the National Science Foundation. MIT MediaLab, 1995. PERRENOUD, P. Dez novas competências para ensinar. Porto Alegre: Artes Médicas Sul, 2000.

PIAGET, J. Aprendizagem e Desenvolvimento. In: PIAGET, J.; GRÉCO, P.

Aprendizagem e Desenvolvimento. Rio de Janeiro: Freitas Bastos, 1974.

PIAGET, J. A equilibração das Estruturas Cognitivas: problema central do desenvolvimento. Zahar Editores, Rio de Janeiro, 1976.

PINSONNEAULT, A.; KRAEMER, K. L. Survey research in management informationsystems: An Assessment. 1993. I.T. in Government, Center for Research on Information Technology and Organizations, UC Irvine Disponível em: http://escholarship.org/uc/item/6cs4s5f0 Acesso em: 12 set. 2013

SCHNEIDER, D. R. Prática Dialógico-Problematizadora dos Tutores na

UAB/UFSM: Fluência Tecnológica no Moodle. Santa Maria: Universidade Federal de Santa Maria, 2011. 185f. Dissertação de Mestrado.

SCHLEMMER, E. Políticas e práticas na formação de professores a distância: por uma emancipação digital cidadã. Disponível em: www.unesp.br/Home/prograd/20110901_102143. DOC Acesso em: 26 out. 2013

SEVERO, C. E. P.; PASSERINO, L.; GLUZ, J. C.; RAMINELLI, A. Mediação

Pedagógica em Ambientes Virtuais de Ensino-Aprendizagem Através de Agentes de Mineração de Dados Educacionais. Informática na Educação: teoria \& prática, Porto Alegre, v. 14, n. 2, p. 63-82, jul./dez. 2011.

SOUZA, A. R. B. de; SARTORI, A. S.; ROESLER, J. Mediação Pedagógica na Educação a Distância: entre enunciados teóricos e práticas construídas. Revista Diálogo Educacional, Curitiba, maio/ago. 2008. Disponível em:

http://www2.pucpr.br/reol/index.php/dialogo?dd1=2009\&dd99=view Acesso em: 02 out. 2013 